\title{
Conceptual Development of the Survival Vehicle: A Mechanism to Promote Resilience and Productivity of Relief Forces in Iran
}

\author{
Fayegh Abdolahzadeh ${ }^{1}$, Farid Allahveisi ${ }^{2} \mathbb{D}$ \\ Date of submission: 31 Aug. $2021 \quad$ Date of acceptance: 9 Sep. 2021
}

\begin{abstract}
INTRODUCTION: The major events occurring in recent decades have demonstrated that human societies are constantly affected by disasters which have always posed a threat to people's lives and properties. The present study aimed to introduce and expand the concept and capacities of "the survival vehicle" in Iran. This descriptive case study was conducted based on an applied research design.

METHODS: This descriptive case study was conducted based on an applied research design. The library research method was used to develop theoretical backgrounds, and to collect information, the field method was employed with observation and researcher's information.

FINDINGS: Considering that rescue forces have to be present at the scene of the disaster for consecutive days and weeks, they are directly exposed to threats, injuries, shortages, and problems as affected people are. Therefore, rescue experts and the Rapid Reaction Team of the Red Crescent Society of Kurdistan Province embarked on designing and using a vehicle called "Survival vehicle" taking into account the priorities in the affected area. This vehicle maintains the strength and motivation of relief forces by meeting their basic needs. Moreover, it increases the productivity of the relief forces and facilitates disaster management by strengthening the resilience of relief workers.

CONCLUSION: As evidenced by the results of the present study, the use of the survival vehicle brings about numerous positive advantages for the members of the Red Crescent rapid response team, as well as relief and operational teams, at the time of crises.
\end{abstract}

Original Article

Keywords: Natural Disasters; Resilience; Relief Forces; Survival Vehicle.

How to cite this article: Abdolahzadeh F, Allahveisi F. Conceptual Development of the Survival Vehicle: A Mechanism to Promote Resilience and Productivity of Relief Forces in Iran. Sci J Rescue Relief 2021; 13(4): 255-62.

\section{Introduction}

$\mathrm{H}$ azards are often defined as serious threats which bring about potential consequences for humans, the economy, or the environment (1), leading to major crises (2). The crisis is the destruction of social order (3). In simple terms, the crisis can be considered the shortage of resources when required (4). Therefore, following a disaster, it may be difficult to provide the needed equipment due to the extent of the damage and confusion. Since these critical and unexpected events strike suddenly, they can bring about numerous problems which are aggravated by inadequate training of people. As a result, communities and individuals need to be educated on pre-disaster planning and preparedness (5). Moreover, they must learn from crises, as well as their own experiences and those of other organizations and communities (6).

For instance, the provision of "rescue bags" in houses is an effective way to mitigate the vulnerability and increase the resilience of people in the event of disasters by meeting the basic and physiological needs of the affected people for several days after the disasters. Moreover, in order to maintain the strength of people, as well as the specialized relief and operational forces, in times of

1- PhD in Disaster and Emergency Health, Department of Disaster Health, School of Management and Medical Information, Isfahan University of Medical Sciences, Isfahan, Iran

2- Master of Executive Management, Islamic Azad University, Sanandaj Branch, Sanandaj, Iran

Corresponding Author: Farid Allahveisi, Email: Farid.allahveisi66@gmail.com 
crisis, other studies and measures have been carried out, for example, " ship's medical bag " (7) and " First Aid Bag for Self-Relief for Infantry. Furthermore, other specialized facilities and equipment have been designed and used in order to promote safety and increase the ability, accuracy, and speed of specialized human resources during search and rescue operations.

In this regard, we can refer to "Sedra" rescue robot", "fire trucks", "rescue vehicles", or "ambulances" which all are indicative of the critical importance of saving human lives in disasters and crises. In addition, other important issues and aspects in times of crisis have been addressed in some studies, including "burnout among relief workers" (11) as well as "factors influencing the effectiveness of rescue and relief teams in response to crises" $(12,13)$. Disaster risk management measures are usually divided into four main stages of prevention (to minimize the likelihood of damage), preparedness and response (focus on rescue), and post-disaster management (to reestablish support services following disasters) (14). The aforementioned issues point to the critical importance of relief workers' preparedness.

For example, natural crises, especially floods, can lead to the spread of numerous diseases (15), presenting a serious threat to the region. Therefore, it calls for relief workers' preparation in such situations; that is to say, they must increase their knowledge to manage emergencies and anticipate the potential necessities. Therefore, the training of relief workers and benefiting from their experiences before disasters increase the readiness of operational forces in the affected area. These programs prepare the rescue teams to face the presented threats and manage disasters $(16,17,18)$; moreover, since the needs and equipment are anticipated in advance, the relief workers do not lose their control over the situation. Therefore, every probable situation must be considered to prevent possible problems. The term "readiness" refers to the ability to respond quickly and appropriately when required (19). Consequently, disaster management requires a systematic approach that is based on awareness, managerial sensitivity, and a deep understanding of the importance of careful planning and organizational readiness.

\section{Methods}

This descriptive case study was conducted based on an applied research design. The library research method was used to develop theoretical backgrounds, and to collect information, the field method was employed with observation and researcher's information.

\section{Findings}

Struggling to survive is central to the concept of saving lives; nonetheless, it assumes neither the importance nor the attention it deserves in public opinion. For example, if we want to go on a halfday trip and get equipment for this trip, we have actually prepared ourselves for the emergency (20). Based on the conditions, this rescue equipment can be placed in a bag or car; in fact, a rescue bag contains the tools which save time in the event of a disaster (21). As mentioned earlier, disasters always lead to serious problems and shortages due to the absence of timely access to the required items, tools, and equipment. Therefore, there will be considerable potential for the emergence of crises and the need for trained relief workers to help disaster-stricken people. This highlights an urgent need for science-backed research to find effective ways to eliminate, avoid, and respond to disasters (22).

Emergency bags, rescue vehicles, ambulance trucks, as well as other necessary tools and equipment, can save people's lives and properties in times of crisis. The survival vehicle is also a valuable and useful tool for the protection of skilled personnel and maintenance of their strengths, motivation, and productivity in the event of a disaster. The readiness of relief workers must follow the path toward the realization of the desired goals, the most important of which is soothing the pain and suffering of the affected people. Relief specialists have the capacity and knowledge to respond to emergencies and provide assistance to people. Nonetheless, the crucial issue to remember is the maintenance of this capability and readiness after the occurrence of disasters. Disaster preparedness programs pursue the following goals: "reduction of fear and anxiety among the relief workers", "prevention of the occurrence and spread of diseases", "paying attention to physical and mental health", "boosting self-confidence", "strengthening relief workers' resilience in the face of disasters," "using their maximum strengths to help the injured", and "trying to create synergy in rescue teams".

The stated vehicle, which is referred to as the "survival vehicle" in this study, was designed by 
the Red Crescent Society and the Rapid Reaction Team of the Red Crescent Society of Kurdistan Province. It has been used in several relief maneuvers and real operations, such as the Kermanshah earthquake in autumn 2018, as well as Kuhdasht and Poldakhtar floods in 2019. It has been proved successful in the improvement of relief workers' resilience, maintenance of their strengths, acceleration of their assigned tasks, as well as the enhancement of their efficiency, effectiveness, and productivity. This car was patented in the winter of 2020(103796).

\section{An introduction to the survival vehicle}

The survival vehicle which has been designed to meet the basic needs of operational forces in the affected area aims to increase operational forces' resilience and productivity, thereby improving rescue operations. It requires relief workers' thorough knowledge of the key survival equipment during rescue operations. Survival equipment refers to minimum items which meet the basic needs of people and relief workers at the scene of the disaster during the rescue operation. These requirements can include various needs, such as the need for accommodation and rest, health and safety, food and safe drinking water, lighting, communications, fuel, and heat. Consequently, this equipment which is intended for a team of 30-40 relief workers is located in a vehicle called a "survival vehicle" which is ready to be sent to the desired location in time of need, along with other forces ( disaster assessment teams, search teams, and other rescuers) or equipment (ambulances, rescue vehicles, fire trucks).

This vehicle must be capable of off-road driving and have a suitable space (cabin) to carry the equipment and tools needed by the rescue forces; furthermore, it must be able to carry out complex maneuvers in different conditions.
Therefore, the vehicle that has been used for this purpose in the current study is Isuzu 6 ton truck which can be replaced with other vehicles in accordance with the conditions. The rear cabin of this car is made of aluminum which is strong enough for the installment of equipment. The cabin has three roller shutters on each side and one roller shutter at the rear; moreover, it has shelves inside, with adequate lighting equipment inside the cab.

This car is also equipped with four adjustable projectors on the four sides of the cabin, two fog lights, a powerful winch, siren, speakers, and wireless. Furthermore, this car has off-road wheels and tires which are able to travel over difficult roads (10). This car also has four floodlights which can be adjusted to a suitable height by a connected elevator, illuminating up to a distance of 150 meters. In addition to the electric motor, city electricity is another power supply of the floodlights. Among the other options of the survival vehicle, we can refer to its $5 \mathrm{kw}$ electric motor which can supply 400 Watts floodlights and other parts of the car in emergency situations.

Due to the type of operation in different conditions and areas, this car can be transformed to a 2-way differential to travel on difficult, uneven, and steep roads. Some specifications of this car include the following (Table 1). Given the characteristics of this type of car, as a result, it can be considered a high-powered vehicle for traveling over steep slopes, roaring waters, snowy passes, and impassable areas. It can carry out difficult maneuvers at night, such as the provision of light due to the possibility of power outages (this was especially evident in the recent floods in the cities of Lorestan province) and can be sent to different parts of the country with diverse climatic conditions (figures 1 and 2).

Table 1. Technical specifications of the used Isuzu 6 ton car (under the title of survival car) Technical specifications and model of vehicle

Engine type

Engine volume

Number of cylinders

Maximum allowable speed

Maximum power (hp / rpm)

Maximum steady speed up the slope

gross weight

Chassis type

Chassis length

Gas tank capacity
ISUZU NPR75K

4HKI-E4N

5193CC

Four Linear actuators (electrical cylinders)

100 kilometers per hour

$150 / 2600$

47

$6000 \mathrm{~kg}$

scalar

$6560 \mathrm{~mm}$

100 liter 


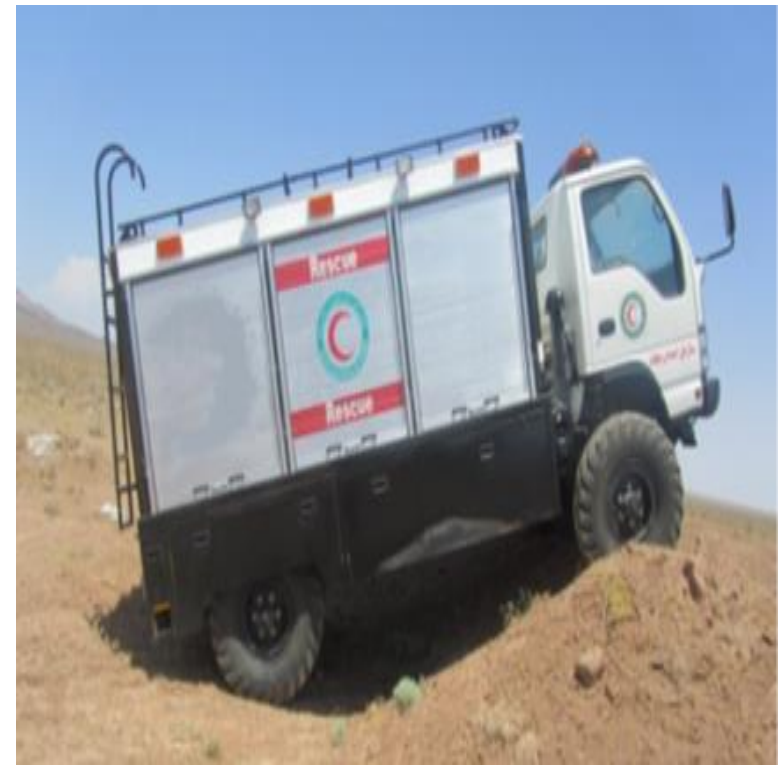

Figure 1. Appearance / overall survival vehicle

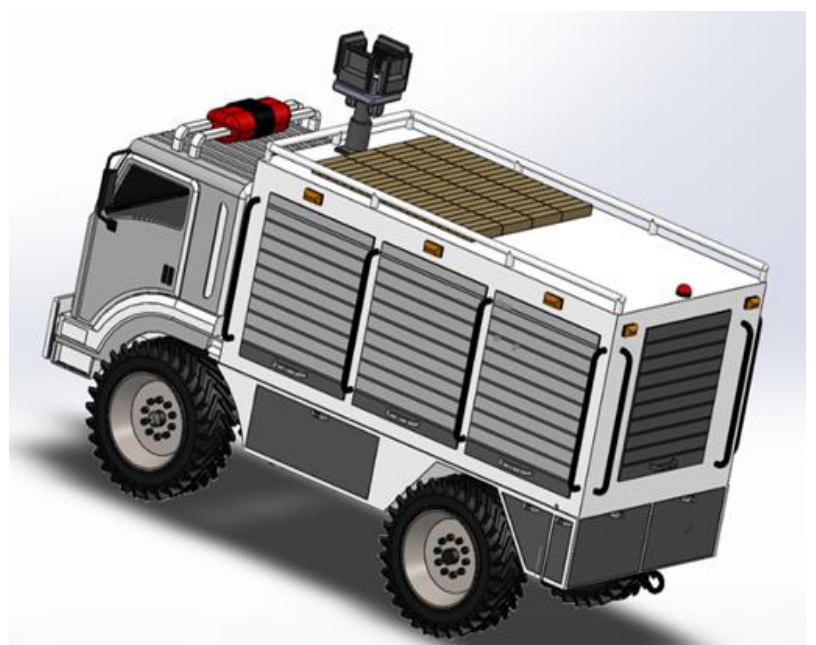

Figure 2. Appearance / overall survival vehicle

\section{Equipment of the survival vehicle}

Given that the survival vehicle contains a set of equipment and items necessary to ensure the health and well-being of rescue workers in times of crisis, it supports the rescue teams in terms of safety and health; moreover, it maintains their strengths and motivation during the relief operation by meeting their basic needs. For instance, one of the issues raised in critical situations is the accommodation of relief and operational forces, and sometimes they are presented with major problems, such as displacement and the long distance of the settlement from the affected area. This in turn leads to less coordination, increased dissatisfaction, and a waste of time in crisis management among relief forces. Moreover, another major concern and complaint of relief forces in the affected area is the lack of a public restroom or the need for water for ablution or taking bath after contact with the deceased.

These shortages have resulted in decreased motivation and strength of relief forces to carry out their rescue operations. These negative consequences were evident among the operational forces in the earthquakes that stroke in Bam, East Azerbaijan, and Kermanshah, as well as the Lorestan flood. Access to healthy food during the operation is another essential requirement in the maintenance of rescue forces' health and strength. For example, rescue workers usually return to their place of residence (miles away) for meals, and this brings about its own risks and expenses 
(such as accidents, waste of time and running out of fuel). They can also receive packaged food items which are usually cold due to the long distance of the disaster site from the food preparation centers. Moreover, it is a waste of time and causes serious risks, such as accidents or other costs.

In addition, the conditions prevailing at the scene of the disaster and the type of relief forces' activities raise the possibility of injury among rescue workers during critical relief activities. Consequently, in the survival vehicle, rescue equipment and first aid are intended for the use of rescue forces in such situations. It is also equipped with a Global Positioning System (GPS) and other navigational equipment (such as a compass), and emergency communication equipment (such as Thuraya satellite phones). Among the other equipment installed in this car, we can refer to necessary facilities for designing emergency accommodation camps for the accommodation of displaced victims in accordance with the conditions and location of the affected area, taking into account the limitations and conditions prevailing in the region. Furthermore, this vehicle is equipped with fire extinguishing capsules for the safety of the relief camp and the forces stationed in the operational area, an electric motor (to provide light in the relief camp), and a water motor (to drain water due to possible rainfall and prevent dangers caused by flooding at the relief camp).

In fact, it can be concluded that the survival vehicle aims at creating a safe and secure relief camp for the rescue forces in the closest safe distance from the disaster site. This camp which contains all necessary equipment to increase the quality of crisis management can provide all the basic needs of relief workers until the end of the rescue operation. This car consists of two parts: passenger compartment (1) and cabin (2) (Figure $3)$. The necessary communication equipment, such as wireless and speakers, as well as other relief communication devices are installed in the passenger compartment. In the cabin, the necessary equipment of rescue forces can be installed, as mentioned. This equipment is provided in the following fields of application for the rescue forces present at the scene of the disaster:

- Appropriate hardware equipment in order to improve the quality of crisis management at the site of operation

-Accommodation and shelter equipment for relief forces (establishment of relief camp)

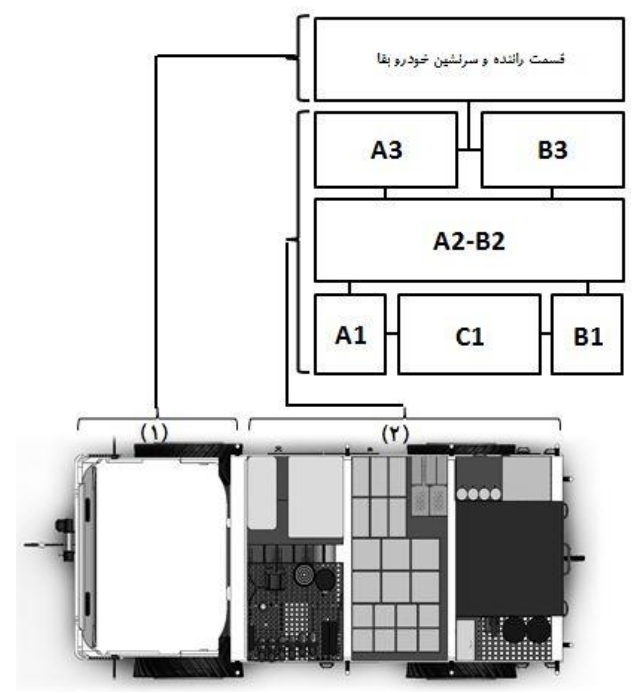

Figure 3. Different parts of the survival vehicle

-Equipment for designing and setting up an emergency camp appropriate to the affected area

First aid and pre-hospital equipment -

- Equipment related to meeting health standards

-Communication and electronic equipment of the rescue forces

-Specialized and individual equipment of the relief forces, depending on the type of hazard

Specialized equipment for searching in different spaces -

-Safety and firefighting equipment

- Equipment for the provision of food for relief forces

-Fuel supply equipment and other possible emergency requirements for ambulances

This equipment is installed in seven cabins as follows:

1. Safety and personal equipment cabin: This cabin is designed for the personal safety equipment of the rescue forces.

2. Food and kitchen equipment cabin: This cabin is dedicated to kitchen equipment and food items (two middle cabins facing each other).

3. First aid equipment cabin: This cabin is for first aid equipment

4. Cabin for camp design equipment and firefighting equipment: This cabin is allocated to fire safety equipment, as well as the necessary equipment for designing the camp in order to 
improve the quality of crisis management operations.

5. Cabin for operation command tents and accommodation: This cabin is dedicated to the equipment for setting up a tent for crisis management operations in the affected area and accommodation of other relief forces. In

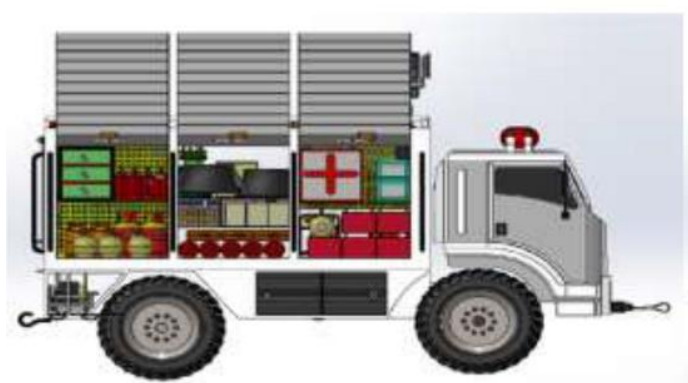

Figure 4. Various items and equipment embedded in auto parts survival

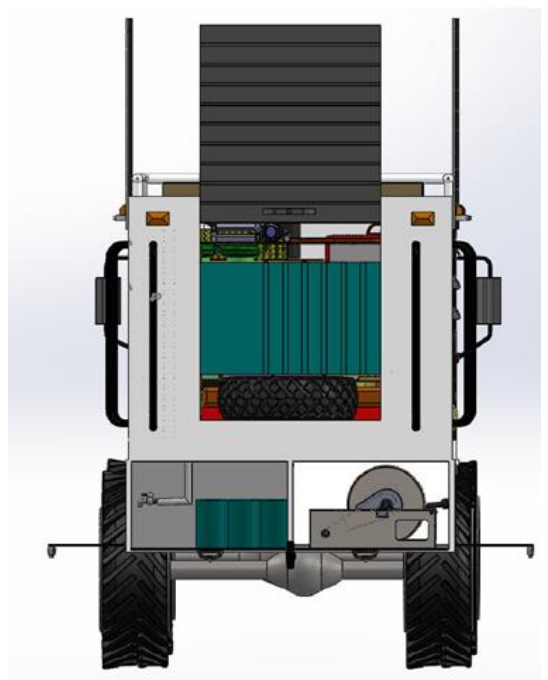

Figure 6. Various items and equipment embedded in auto parts survival

\section{Discussion and Conclusion}

Iran is one of the most disaster-prone countries in the world in terms of geographical location, climate, and geopolitical characteristics. It is considered the fourth country in Asia and the sixth country in the world in terms of the frequency of disasters (23), with a share of $6 \%$ of all reported natural disasters across the globe (24). It can be stated that every generation of Iranians experiences disastrous events, such as earthquakes and floods, at least twice or more in their lifetime (25). The occurrence of these disasters requires the continuous and effective presence of relief and addition to this equipment, bathing and toilet equipment are located in this cabin.

6. Water tank cabin: This cabin is designed for water storage tank and filter, pipes and fittings, and spare tires.

The aforementioned items are displayed in figures 4-7.

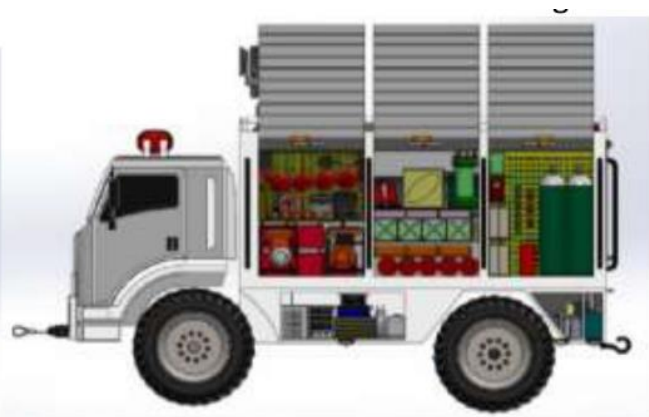

Figure 5. Various items and equipment embedded in auto parts survival

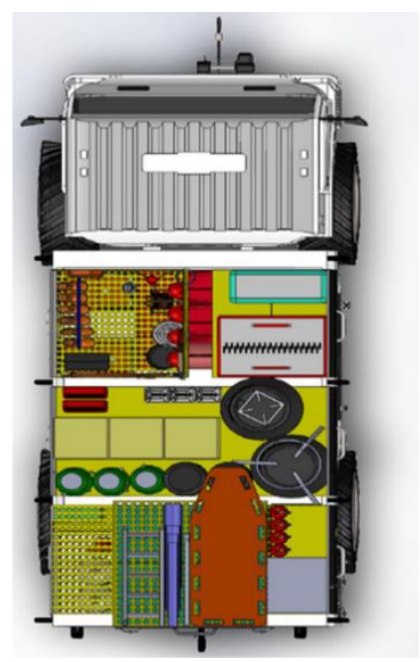

Figure 7. Various items and equipment embedded in auto parts survival

operational forces in the affected area. In some cases, depending on the situation, rescue forces may work in the affected area for consecutive days and weeks. As a result, they will always face many security, health, well-being, and welfare problems at the scene of the disaster. Nonetheless, in most cases, due to the critical situation in the region, it is impossible or difficult to meet these needs and resolve these problems in the affected area. This in turn leads to decreased motivation, resilience, and effectiveness, as well as increased burnout, dissatisfaction, and vulnerability of relief workers.

Therefore, meeting the needs of rescue forces, as well as increasing resilience and coordination, 
during disaster relief missions has received assiduous attention. The type and importance of relief forces' activities in times of crises, as well as the conditions prevailing in the affected area, highlight the importance of meeting the basic needs of operational forces (such as security, food, health, and accommodation). Consequently, rescue forces' motivation and strength would be increased, which in turn leads to the maintenance of their maximum productivity and improvement of their efficiency in the event of catastrophic disasters. This issue assumes critical importance since in recent years, we have witnessed the dissatisfaction of rescue forces and their fatigue in the first days after the disasters which can be ascribed to the absence of a suitable resting place, health, security, as well as fear of the spread of epidemics among the relief and specialized forces.

Numerous studies have been conducted in Iran on the importance of physical, mental, and psychological health services provided to people $(26,27)$ and of course, the relief forces in times of crisis. Nonetheless, all of them have dealt with different aspects of the post-disaster response, and there is a dearth of studies on the prevention and mitigation of hazards, as well as the maintenance of relief forces' strengths. Therefore, there is a research gap in the field of preventive and risk reduction measures for relief and specialized forces. For instance, ambulances, rescue vehicles, and fire trucks are equipped with facilities to help people in the affected area.

Nevertheless, it should be borne in mind that relief and operational forces must first and foremost maintain their strength and motivation until the end of various search and rescue operations so that they can continue to provide appropriate services throughout the mission. However, this type of equipment is not installed in any of these vehicles, and this issue has not been so far studied in a coherent and comprehensive manner. The conducted studies have attributed the decreased strength and satisfaction of specialized forces to the issues related to health, food, rest, safety, security, and welfare in the affected region.

The present study aimed to introduce the concept of "survival vehicle" (patent number: 103796) considering the issues raised by the rescue forces in times of crisis and during relief operations to ensure security, health, food, and welfare of relief forces, maintain their strength and motivation, reduce their vulnerability, and increase their resilience in post-crisis situations. As mentioned earlier, this vehicle was tested in two maneuvers by the experts of the Rapid Reaction Team of the Red Crescent Society of Kurdistan Province, and it has been then used in two extra-provincial disaster operations. Based on the evaluations and evidence, the utilization of this vehicle increases the resilience and satisfaction of specialized rescue forces, and consequently, their productivity in various disaster relief missions.

Moreover, the use of this vehicle in the affected areas will minimize the dependence of the rescue team on the facilities of the affected region and increase their self-reliance. Furthermore, the equipment and facilities located in the survival vehicle can be useful and effective in the creation of synergy in the assigned tasks and activities of the Operations Command Center, as well as the accommodation of relief workers. Moreover, this vehicle enables those in charge to closely control and monitor the performed activities and make the best of relief forces' experiences. As a result, the survival vehicle sets up an equipped relief camp at the nearest safe place from the scene of the disaster.

The basic needs of relief forces during disasters are provided in this car and available to the relief forces in the shortest time possible. Moreover, it minimizes the requirements of the operational forces sent to the affected area and enables them to provide their needs without dependence on the site of the disaster. Consequently, the fulfillment of relief forces' needs will improve their resilience, performance, and health, as well as the quality of crisis management in the affected area. Moreover, it makes it possible for relief workers to communicate in all situations.

\section{Acknowledgments}

The authors would like to express their gratitude to all those who contributed to the conduction of this research project.

\section{Conflict of Interests}

Authors declared no conflict of interests regarding the publication of the present study.

\section{References}

1. UNISDR terminology on disaster risk reduction. 
UNDRR 2009

2. Parker CF, Nohrstedt D, Baird J, Hermansson H, Rubin O, Baekkeskov E, et al. Collaborative crisis management: a plausibility probe of core assumptions. Policy Soc 2020; 39(4):1-20.

3. Mostafavi SH, Sayadi A, Pourezzat A, Damadi H, Motahedin M. Designing a system for mobilizing national facilities to deal appropriately with natural and social crises. Kamal Management 2004. (In Persian)

4. Abdi MH, Kakahjob A, Hashemi M. Application of hierarchical analysis process in locating open spaces in order to manage the crisis of the case study of the central context of Sanandaj 2016:46-57. (In Persian)

5. Tabish SA, Nabil S. Disaster Preparedness: Current Trends and Future Directions. Int J Sci Res 2015;4(6):227-252

6. Alzoubi MO. The Impact of Management Information System's Features on Crisis Management in Jordanian Commercial Banks (Field Study on Jordanian Commercial Banks in the Northern Sector). J. Asian Sci. Res 2020:165-179.

7. Nobakht M. Design of relief bag (ship's medical bag) for light and semi-heavy vessels based on the type of possible injuries. Second National Conference on Drowning Prevention 2018. (In Persian)

8. Hashemzadeh M, Salari M, Pishgooie A, Ebadi A, Abbasi P. Design and Construction of the First Aid Bag for Self-Relief for Infantry Forces: Hybrid Study 2018:364-370. (In Persian)

9. Moghdari A, Amiri F, Mahboubi H, Aaskari Mahalla A, Baghani A, Pishkenari H, Karimi R, Khaliqi Y, et al. Design and construction of "Sedra" rescue robot with special capabilities 2004. (In Persian)

10. Jangi R, Jafari A, Akbarpour A, Moshari A. Guide to using rescue equipment 2016. (In Persian)

11. Barati Sedeh F. Status of relief burnout in a group of service providers compared to inactive rescuers in Bam earthquake 2009. (In Persian)

12. Chaharsoughi Amin H, Shiri SH, Noori H, Tardast H. Factors affecting the effectiveness of rescue teams in Ilam province. Sci J Rescue and Relief 2014; 6(3). (In Persian)

13. Nisi AK, Wise M, Tardast $H$. Investigating the effective factors on the effectiveness of rescue teams to respond to crises in Ilam province Sci $\mathbf{J}$ Rescue and Relief 2014;6(2). (In Persian)

14. Cozannet G Le, Kervyn M, Russo S, Ifejika Speranza C, Ferrier P, Foumelis M, Lopez T, Modarresi H, et al. Space Based Earth Observations for Disaster Risk Management. Surveys in Geophysics 2020.

15. Fazaeli M, Rashidi M. The relationship between water security and natural disasters in international law 2019:131-154 (In Persian)

16. Denis G, de Boissezon H, Hosford S, Pasco X, Montfort B, Ranera F. The evolution of Earth Observation satellites in Europe and its impact on the performance of emergency response services. Acta Astronaut 2016; 127:619-633.

17. Klomp J. Economic development and natural disasters: a satellite data analysis. Global Environ Change Hum Policy Dimens 2016; 36:67-88.

18. Voigt S, Kemper T, Riedlinger T, Kiefl R, Scholte $\mathrm{K}$, Mehl H. Satellite image analysis for disaster and crisis-management support. IEEE Trans Geosci Remote Sens 2007; 45(6):1520-1528.

19. Hosseini Jenab V, Jalali A, Seyedi M, Jafari M. Earthquake resilience and crisis management planning and Japanese experiences. Hilal Iran Institute of Higher Education 2013. (In Persian)

20. Ayoubian Z. Family rescue bag. Helal Iran Institute of Higher Education 2011. (In Persian)

21. Abbasi A, Hamdarsi N. Rescue bag. Third International Congress on Health, Treatment and Crisis Management 2006. (In Persian)

22. Allahveisi F, Ahmadi K, Mohammadi M. The Role of Strategic Thinking in the Quality of Crisis Management Operations. Int J Bus Manag 2019; 4(2):113-121.

23. Allahveisi F, Ahmadi K. Comprehensive Disaster management by community-based and Foresight (1st edition).Iran. Tehran Commercial printing and publishing Co 2019. (In Persian)

24. Nasehi A, Imani M. Investigating the importance of religious rulings required by rescuers and local people in natural disasters. Sci J Rescue and Relief 2010; 2(2):55-64. (In Persian)

25. Babakhamseh F. Provide a practical model of the accident control system in the hospitals of the Social Security Organization (proposed) using "HEICS" The second scientific research conference of rescue management 2005:123-125 (In Persian)

26. Khankeh H, Mohammadi R, Ahmadi F. The state of health care delivery in the event of a natural disaster: A qualitative study. Iran J Nurs Res 2007; 20(51):85-96. (In Persian)

27. Eyvaz zadeh R, Janani A. Mental disorders, and mental health. Third International Congress on Health and Emergency Management 2006. (In Persian) 